\title{
Reducing Root Galling Caused by Root Knot Nematodes in Black Pepper (Piper nigrum L. cv. 'Kuching') through Nutrient Supplementation
}

\author{
Babirye Khadijah $^{1}$, Patricia King Jie Hung ${ }^{1,2^{*}}$, Zahora Binti Ismail ${ }^{2}$ and Ong Kian Huat ${ }^{1}$ \\ Received: $24^{\text {th }}$ June 2021 / Accepted: 01 ${ }^{\text {st }}$ November 2021
}

\begin{abstract}
Purpose: Root-knot nematodes (RKN) remain one of the leading causes of economic damage in black pepper (Piper nigrum L.) cultivation worldwide. An experiment was conducted to evaluate the response of black pepper plants to RKN when irrigated with three nutrient solutions; Hoagland solution only, Hoagland solution $+0.005 \mathrm{mM}$ potassium silicate solution, and Hoagland solution $+2 \mathrm{mM}$ salicylic acid solution.

Research Method: Plants grown in medium-sized polybags were inoculated with RKN and routinely irrigated with the appropriate nutrient solutions. Presence of foliar symptoms of RKN infection on plants, their aerial growth plus root infestation were assessed. Superoxide anion and hydrogen peroxide production from the plant leaves were also detected after inoculation.
\end{abstract}

Findings: Foliar symptoms of RKN infection started manifesting after 81 days from inoculation. Plants without silicate or salicylic acid supplementation displayed the most severe foliar disorder symptoms, highest root galling and the shortest aerial growth. Plants irrigated with potassium silicate had the highest aerial growth and their leaves showed the least oxidative stress when challenged with RKN.

Originality/value: From present results, soil amendment with potassium silicate is a promising tool for reducing root galling and promoting aerial growth in $R K N$-infested black pepper fields.

Keywords: Hoagland solution, Induced plant health, Potassium silicate, Reactive oxygen species, Root galls, Salicylic acid

\section{INTRODUCTION}

Black pepper (Piper nigrum L.) is a perennial vine whose berries are highly valued as a spice and a medicine (Izzah and Wan Asrina, 2019). It is an economically important crop in Malaysia and an important cash crop of Sarawak (Izzah and Wan Asrina, 2019). 'Kuching' is one of the traditional cultivars grown with high yields but it is highly prone to major root diseases, e.g., root knot nematodes (RKN) (Izzah and Wan Asrina, 2019). In Malaysia, RKN are ubiquitous, severely damage black pepper roots (Trinh, 2010) and are among the major causes of reduced yields and quality in black pepper (Ravindra et al., 2014). Therefore, eco-friendly strategies to reduce RKN infestation in black pepper are required, especially owing to the fact that a given black pepper farm can be infested by many RKN species at one time (Trinh, 2010). The RKN problem can be escalated if the nematode species favour the available weeds in a given field (Naz et al., 2012).

Among the advances employed to control RKN include crop rotation, application of wide spectrum of chemical nematicides plus use of resistance genes (Mitkowski and Abawi, 2003), use of bioagents (Naz et al., 2020), grafting

\footnotetext{
${ }^{1}$ Faculty of Agricultural Sciences and Forestry, Universiti Putra Malaysia, 97000 Bintulu, Sarawak, Malaysia

${ }^{2 *}$ Institute of Ecosystem Science Borneo, Universiti Putra Malaysia, 97000 Bintulu, Sarawak, Malaysia

patricia@upm.edu.my

(D) https://orcid.org/0000-0003-4522-0165
} 
susceptible varieties onto nematode-resistant rootstocks (Sim and Rosmah, 2011), besides others. Each of the above advances has associated challenges that limit its sustainability; the broad host spectrum of RKN species limits the use of crop rotation (Mitkowski and Abawi, 2003). Fumigants and nematicides pose a threat to both humans and the ecosystem due to their gradual environmental toxicities (Naz et al., 2020). Efforts to graft $P$. nigrum shoots onto $P$. colubrinum rootstocks yielded high initial success but graft incompatibility (Sim and Rosmah, 2011) led to poor plant survival (Lau et al., 2012).

Although silicon ( $\mathrm{Si}$ ) is a non-essential nutrient, its roles in disease/pathogen suppression and in regulation of plant nutrient uptake have been highlighted in previous works (Laane, 2018). Amendment of soil with $\mathrm{Si}$ has successfully decreased the RKN reproduction rate, root galling, population density and overall RKN development in cucumber, rice, sugarcane, coffee, among others (El-sherif et al., 2016; Zhan et al., 2018). Several related reports have revealed an increasing interest in inducing $\mathrm{RKN}$ resistance using exogenous salicylic acid (SA) in different crops e.g. okra, tomatoes, cowpeas, among others (Molinari et al., 2014; Moslemi et al., 2016). In many plant-pathogen interactions, SA has been linked with $\mathrm{H}_{2} \mathrm{O}_{2}$ accumulation during regulation of plant defence responses (Matthew and Olubukola, 2019). Additionally, exogenous SA has been extensively used in improving nutrient uptake, stimulating vegetative growth and root development (Pasternak et al., 2019). Therefore, irrigating black pepper seedlings with nutrient solutions supplemented with exogenous $\mathrm{Si}$ and SA provides hope for production of healthier roots which are less susceptible to RKN infestation.

Production of hydrogen peroxide, superoxide anions, among other reactive oxygen species (ROS) is one of the many defence responses exhibited by plants (Ali et al., 2018). Pietrowska et al., 2014 observed the superoxide anion $\left(\mathrm{O}_{2} \bullet-\right.$ ) generation was almost doubled in the leaves of tested plants after inoculation with fungal pathogen as compared to the non-inoculated cultures from 6 hours post inoculation. Similarly, infestation of plant roots by RKN subjects plants to oxidative stress, which manifests as increased production of ROS. Hydrogen peroxide $\left(\mathrm{H}_{2} \mathrm{O}_{2}\right)$ accumulation is reflective of oxidative stress in the plant and a characteristic of increased defence responses by the plant, during and after successful microbial infection (Nicholas and Dominique, 2019). Hydrogen peroxide accumulation is known to increase during disease development, as proved in tomato leaf tissues and sugarcane plants (Pietrowska et al., 2014; Ashwin et al., 2018).

Although information regarding the use of ROS detection approach to diagnose RKN infestation in black pepper fields is still lacking in the available literature, its application and/or adoption could provide timely insights onto the extent of RKN infestation in black pepper farms and ultimately reveal which nutrient composition protects RKN-inoculated black pepper plants from deleterious oxidative impact.

The current study aimed to evaluate the impact of potassium silicate and exogenous SA amendments in the nutrient solution, on RKN infestation in black pepper ( $P$. nigrum cv. 'Kuching') plants. This study also aimed at evaluating the oxidative stress by assessing the production of superoxide anion $\left(\mathrm{O}_{2} \bullet-\right)$ and hydrogen peroxide $\left(\mathrm{H}_{2} \mathrm{O}_{2}\right)$ in black pepper leaves after inoculation of the plant rhizosphere with RKN. From our knowledge, this will be the first study documenting the influence of RKN on black pepper plants by the use of potassium silicate and detecting the production of ROS in leaves of black pepper plants inoculated with RKN. Because of the significance of Sarawak black pepper production to Malaysia's economy, positive results of this study can be exploited by both future researchers and black pepper farmers.

\section{MATERIALS AND METHODS}

Black pepper ( $P$. nigrum cv. 'Kuching') stem cuttings with 2-3 nodes were obtained from the Malaysian Pepper Board and hydroponically planted in three nutrient media namely; Hoagland solution only $\left(\mathrm{T}_{1}\right)$, Hoagland solution $+0.005 \mathrm{mM}$ potassium silicate solution $\left(\mathrm{T}_{2}\right)$ and Hoagland solution $+2 \mathrm{mM}$ salicylic acid 
solution $\left(\mathrm{T}_{3}\right)$. Hoagland solution $\left(\mathrm{T}_{1}\right)$ was used as the baseline nutrient medium i.e. negative control formulation. Nutrient salts used included Hoagland's No. 2 basal salt mixture powder (Sigma-Aldrich, USA), potassium silicate (sigma-Aldrich, Canada), Salicylic acid (Merck, China), among others. After 12 weeks of hydroponic culturing, each black pepper plant was carefully transplanted into $23 \mathrm{~cm} \times 15 \mathrm{~cm}$ sized polybags containing moist autoclaved soil (loam sand - 1:1 v/v). These plants were transferred to the green house, organised in a completely randomized design, followed by irrigation of each plant with its treatment every 5 days throughout the experimental period. Each nutrient medium i.e. $\mathrm{T}_{1}, \mathrm{~T}_{2}, \mathrm{~T}_{3}$ comprised of 3 replicates, each containing 15 plants.

Root knot nematodes (Meloidogyne species) were sourced from soil samples collected from a black pepper farm infested with RKN in Bintulu-Sarawak, Malaysia. Approximately 500 $\mathrm{g}$ soil from the rhizosphere of each galled root system was collected and transported in coolers to the laboratory for extraction of Meloidogyne species, following the tray/sieving procedure modified from Whitehead and Hemming (1965). Pre-sieved $200 \mathrm{~mL}$ soil subsamples were wetted and spread out thinly on stainless steel sieves (BS410, Malaysia) of different apertures stacked in sequence, namely $150,75,45 \mu \mathrm{m}$, respectively. A filter paper (Whatman, $150 \mathrm{~mm}$ ) was placed on top of the $45 \mu \mathrm{m}$ sieve resting in a collecting dish, after which the experiment was left to stand for 12 hours. The filtrate in the collecting dish was carefully poured into a measuring cylinder and the supernatant was carefully sucked off using a pipette, leaving the nematode suspension (Meloidogyne species inoculum) in the cylinder. Morphological species identification of the nematode inocula revealed a mixture of more than one Meloidogyne species in the soil samples and the presence of egg cases, second-stage juveniles and adult male Meloidogyne species (data not shown). Using a pipette, $30 \mathrm{~mL}$ of the Meloidogyne species inoculum was inoculated $7 \mathrm{~cm}$ deep into the root rhizosphere of each experimental plant, at an inoculation distance of $3 \mathrm{~cm}$ from the experimental plant's stem base. A total of $15 P$. nigrum cv. 'Kuching' plants from each treatment ( 5 random plants from each replicate), were not inoculated and thus served as control samples. Experimental plants were continuously monitored for presence of any foliar symptom of RKN infection.

Assessment of the impact RKN had on shoot criteria in each treatment composition was carried out every 07 days after inoculation (dai) i.e. at 07 , 14, 21, until 140 (end of the experiment). Total number of spikes, new leaves, leaf area of new leaves, shoot height, and number of new nodes were the growth assessments made. Leaf area was calculated from an indirect non-destructive method proposed by De Swart et al. (2004) and adopted in Khan et al. (2016)'s study; LA $=0.690 \times \mathrm{L} \times \mathrm{W}$ where LA $=$ Leaf Area $(\mathrm{cm})^{2}$, $\mathrm{L}=$ leaf length $(\mathrm{cm})$ and $\mathrm{W}=$ leaf width $(\mathrm{cm})$. For assessment of root galls on the root system of inoculated $P$. nigrum cv. 'Kuching' plants, randomly-selected symptomatic plants from each treatment were uprooted at 140 dai, their roots gently washed in tap water and blotted until dry.

In vivo detection of superoxide anion $\left(\mathrm{O}_{2} \cdot-\right)$ and hydrogen peroxide $\left(\mathrm{H}_{2} \mathrm{O}_{2}\right)$ in leaves of $P$. nigrum cv. 'Kuching' plants inoculated with Meloidogyne species was done every 05 days after inoculation (dai) i.e. at 0, 05, 10, 15, 20 and at 25 . On each of these sampling days, three leaves (second-young leaf) from different plants of the same treatment were randomly selected for each treatment composition and used as samples for the $\mathrm{O}_{2} \bullet$ - assay. On the same days, a similar procedure was repeated for samples used in the $\mathrm{H}_{2} \mathrm{O}_{2}$ assay. Leaves were excised from the plants, their petioles were immediately wrapped with wet tissue paper to minimize water loss after excising and were quickly transferred in coolers to the laboratory. Detection of hydrogen peroxide and superoxide anions were done using the 3,3' diaminobenzidine (DAB) and Nitro Blue Tetrazolium (NBT) assays respectively, following Kumar et al. (2014)'s histochemical protocols. Data were processed using the SAS software version 9.2 and the Shapiro-Wilk test was employed to check data normality. Mean separations were performed through the Duncan's multiple range test, at 0.05 probability level. 


\section{RESULTS}

Foliar Symptoms of infection exhibited by $P$. nigrum cv. 'Kuching' plants inoculated with Root Knot Nematodes

Foliar symptoms of root knot nematode (RKN) infection in P. nigrum cv. 'Kuching' plants were first observed in plants irrigated with Hoagland solution only $\left(\mathrm{T}_{1}\right)$ at 81 days after inoculation (dai) (Table 01). These symptoms were manifested as; (i) non-uniform leaf yellowing (ii) wilted upper leaves and (iii) leaf defoliation. Generally, plants displaying foliar RKN infection symptoms followed the order; $\mathrm{T}_{1}>\mathrm{T}_{3}>\mathrm{T}_{2}>$ uninoculated plants. Leaves of inoculated plants irrigated with Hoagland solution supplemented with potassium silicate $\left(\mathrm{T}_{2}\right)$ appeared healthy and uniformly green even by 95 dai (Table 01 ). Similarly, the shoot system of uninoculated plants appeared healthy and uniformly green even at 102 dai. Infection symptoms in uninoculated plants slowly started manifesting at 109 days of experimentation, displaying a few leaves with non-uniform yellowing i.e. $0.13 \pm 0.07$ leaves.

\section{Effect of Root Knot Nematodes on the aerial growth of $P$. nigrum cv. 'Kuching' plants irrigated with Different Treatment Compositions}

The first spike was observed at 49 dai in $\mathrm{T}_{2}$ plants (Table 02) and this treatment composition promoted production of the significantly highest total number of spikes throughout the experimental period, with $38.25 \pm 0.21$ spikes at 140 dai. $T_{1}$ and $T_{3}$ plants generally produced similar total number of spikes. Results in Table 03 indicate that $\mathrm{T}_{2}$ favoured production of the significantly highest number of new leaves i.e. $39.02 \pm 0.11$ at 140 dai. Additionally, plants irrigated with $\mathrm{T} 2$ produced the significantly highest shoot height, leaf area of new leaves, and the highest number of new nodes followed by plants irrigated with $\mathrm{T} 3$ i.e. $\mathrm{T}_{2}>\mathrm{T}_{3}>\mathrm{T}_{1}$ (Tables 04, 05 and 06, respectively).

Table 01: $\quad$ Total number of $P$. nigrum cv. 'Kuching' plants exhibiting foliar symptoms of root knot nematode infection.

\begin{tabular}{ccccc}
\hline \multirow{2}{*}{$\begin{array}{c}\text { Days after } \\
\text { inoculation }\end{array}$} & \multicolumn{3}{c}{ Total No. of plants exhibiting foliar symptoms of root knot nematode infection } \\
\cline { 2 - 5 } & Treatment 1 & Treatment 2 & Treatment 3 & Uninoculated plants \\
\hline 81 & $5.88 \pm 0.02^{\mathrm{a}}$ & $0.0000^{\mathrm{a}}$ & $0.0000^{\mathrm{a}}$ & $0.0000^{\mathrm{a}}$ \\
88 & $11.76 \pm 0.09^{\mathrm{a}}$ & $0.0000^{\mathrm{b}}$ & $7.14 \pm 0.03^{\mathrm{a}}$ & $0.0000^{\mathrm{b}}$ \\
95 & $17.65 \pm 0.06^{\mathrm{a}}$ & $0.0000^{\mathrm{b}}$ & $21.43 \pm 0.02^{\mathrm{a}}$ & $0.0000^{\mathrm{b}}$ \\
102 & $23.78 \pm 0.48^{\mathrm{a}}$ & $3.43 \pm 1.10^{\mathrm{b}}$ & $23.35 \pm 0.67^{\mathrm{a}}$ & $0.0000^{\mathrm{b}}$ \\
109 & $24.39 \pm 0.21^{\mathrm{a}}$ & $12.20 \pm 0.01^{\mathrm{b}}$ & $29.26 \pm 0.52^{\mathrm{a}}$ & $0.13 \pm 0.07^{\mathrm{c}}$ \\
116 & $27.01 \pm 0.29^{\mathrm{a}}$ & $18.24 \pm 1.11^{\mathrm{b}}$ & $33.41 \pm 0.29^{\mathrm{a}}$ & $4.11 \pm 0.47^{\mathrm{c}}$ \\
123 & $32.40 \pm 0.09^{\mathrm{a}}$ & $23.81 \pm 0.53^{\mathrm{b}}$ & $33.96 \pm 0.30^{\mathrm{a}}$ & $7.46 \pm 0.73^{\mathrm{c}}$ \\
130 & $33.30 \pm 0.15^{\mathrm{a}}$ & $25.40 \pm 0.00^{\mathrm{b}}$ & $38.23 \pm 0.55^{\mathrm{a}}$ & $7.60 \pm 0.91^{\mathrm{c}}$ \\
137 & $43.76 \pm 0.20^{\mathrm{a}}$ & $25.62 \pm 0.10^{\mathrm{b}}$ & $41.46 \pm 0.77^{\mathrm{a}}$ & $12.87 \pm 1.13^{\mathrm{c}}$ \\
144 & $55.99 \pm 0.30^{\mathrm{a}}$ & $29.87 \pm 0.09^{\mathrm{c}}$ & $43.32 \pm 0.61^{\mathrm{b}}$ & $16.78 \pm 1.07^{\mathrm{d}}$ \\
\hline
\end{tabular}

Values in the Table Oare Mean \pm standard deviation. Means with the same superscript in the row are not significantly different at P $\leq$ 0.05 using Duncan's Multiple Range Test 
Table 02: $\quad$ Total number of spikes produced by $P$. nigrum $\mathrm{cv}$. 'Kuching' plants inoculated with root knot nematodes.

\begin{tabular}{cccc}
\hline \multirow{2}{*}{$\begin{array}{c}\text { Days after } \\
\text { inoculation }\end{array}$} & \multicolumn{3}{c}{ Number of spikes } \\
\cline { 2 - 4 } & Treatment 1 & Treatment 2 & Treatment 3 \\
\hline 49 & $0.0000^{\mathrm{a}}$ & $2.67 \pm 0.70^{\mathrm{a}}$ & $0.0000^{\mathrm{a}}$ \\
56 & $4.47 \pm 0.20^{\mathrm{ab}}$ & $6.37 \pm 0.88^{\mathrm{a}}$ & $2.46 \pm 0.50^{\mathrm{b}}$ \\
63 & $5.96 \pm 0.22^{\mathrm{a}}$ & $6.47 \pm 0.51^{\mathrm{a}}$ & $4.26 \pm 0.71^{\mathrm{b}}$ \\
70 & $6.15 \pm 0.45^{\mathrm{a}}$ & $7.83 \pm 0.57^{\mathrm{a}}$ & $6.05 \pm 0.93^{\mathrm{a}}$ \\
77 & $9.48 \pm 0.62^{\mathrm{b}}$ & $13.62 \pm 0.91^{\mathrm{a}}$ & $7.32 \pm 0.41^{\mathrm{b}}$ \\
84 & $9.82 \pm 0.35^{\mathrm{b}}$ & $14.97 \pm 0.70^{\mathrm{a}}$ & $8.07 \pm 0.88^{\mathrm{b}}$ \\
91 & $10.89 \pm 0.58^{\mathrm{b}}$ & $15.83 \pm 0.50^{\mathrm{a}}$ & $13.45 \pm 0.20^{\mathrm{ab}}$ \\
98 & $14.39 \pm 0.60^{\mathrm{a}}$ & $15.93 \pm 0.58^{\mathrm{a}}$ & $14.70 \pm 0.28^{\mathrm{a}}$ \\
105 & $16.91 \pm 0.18^{\mathrm{a}}$ & $18.62 \pm 0.74^{\mathrm{a}}$ & $19.19 \pm 0.81^{\mathrm{a}}$ \\
112 & $17.18 \pm 0.52^{\mathrm{b}}$ & $26.72 \pm 0.09^{\mathrm{a}}$ & $22.93 \pm 0.18^{\mathrm{ab}}$ \\
119 & $19.20 \pm 0.73^{\mathrm{b}}$ & $29.52 \pm 0.55^{\mathrm{a}}$ & $26.05 \pm 0.37^{\mathrm{a}}$ \\
126 & $24.33 \pm 0.63^{\mathrm{b}}$ & $32.32 \pm 1.02^{\mathrm{a}}$ & $26.26 \pm 0.60^{\mathrm{b}}$ \\
133 & $27.55 \pm 0.43^{\mathrm{b}}$ & $35.16 \pm 0.10^{\mathrm{a}}$ & $28.79 \pm 0.15^{\mathrm{b}}$ \\
140 & $29.02 \pm 0.28^{\mathrm{b}}$ & $38.25 \pm 0.21^{\mathrm{a}}$ & $29.18 \pm 0.31^{\mathrm{b}}$ \\
\hline
\end{tabular}

Values in the Table Oare Mean \pm standard deviation. Means with the same superscript in the row are not significantly different at $P \leq$ 0.05 using Duncan's Multiple Range Test

Table 03: Number of new leaves of $P$. nigrum cv. 'Kuching' plants inoculated with root knot nematodes.

\begin{tabular}{cccc}
\hline \multirow{2}{*}{$\begin{array}{c}\text { Days after } \\
\text { inoculation }\end{array}$} & \multicolumn{3}{c}{ Number of new leaves } \\
\cline { 2 - 4 } & Treatment 1 & Treatment 2 & Treatment 3 \\
\hline 7 & $0.33 \pm 0.88^{\mathrm{b}}$ & $0.37 \pm 0.50^{\mathrm{b}}$ & $2.14 \pm 0.20^{\mathrm{a}}$ \\
14 & $1.16 \pm 0.45^{\mathrm{b}}$ & $0.62 \pm 0.35^{\mathrm{b}}$ & $2.01 \pm 0.62^{\mathrm{a}}$ \\
21 & $1.19 \pm 0.04^{\mathrm{b}}$ & $0.81 \pm 0.01^{\mathrm{b}}$ & $1.92 \pm 0.05^{\mathrm{a}}$ \\
28 & $2.00 \pm 0.88^{\mathrm{a}}$ & $0.71 \pm 0.50^{\mathrm{b}}$ & $1.51 \pm 0.20^{\mathrm{ab}}$ \\
35 & $3.50 \pm 0.24^{\mathrm{a}}$ & $1.54 \pm 0.35^{\mathrm{b}}$ & $1.68 \pm 0.62^{\mathrm{b}}$ \\
42 & $4.11 \pm 0.05^{\mathrm{a}}$ & $3.45 \pm 0.04^{\mathrm{ab}}$ & $2.84 \pm 0.09^{\mathrm{b}}$ \\
49 & $4.32 \pm 0.18^{\mathrm{b}}$ & $6.68 \pm 0.35^{\mathrm{a}}$ & $3.38 \pm 0.58^{\mathrm{b}}$ \\
56 & $5.14 \pm 0.11^{\mathrm{ab}}$ & $6.61 \pm 0.13^{\mathrm{a}}$ & $3.46 \pm 0.24^{\mathrm{b}}$ \\
63 & $5.78 \pm 0.16^{\mathrm{a}}$ & $6.97 \pm 0.11^{\mathrm{a}}$ & $3.72 \pm 0.23^{\mathrm{b}}$ \\
70 & $4.85 \pm 0.59^{\mathrm{b}}$ & $8.46 \pm 0.44^{\mathrm{a}}$ & $4.03 \pm 0.47^{\mathrm{b}}$ \\
77 & $4.75 \pm 0.26^{\mathrm{b}}$ & $9.73 \pm 0.35^{\mathrm{a}}$ & $4.45 \pm 0.13^{\mathrm{b}}$ \\
84 & $6.93 \pm 0.08^{\mathrm{b}}$ & $11.09 \pm 0.07^{\mathrm{a}}$ & $7.81 \pm 0.03^{\mathrm{b}}$ \\
91 & $8.06 \pm 0.26^{\mathrm{b}}$ & $15.29 \pm 0.28^{\mathrm{a}}$ & $8.89 \pm 0.21^{\mathrm{b}}$ \\
98 & $9.04 \pm 0.01^{\mathrm{b}}$ & $16.43 \pm 0.07^{\mathrm{a}}$ & $9.04 \pm 0.20^{\mathrm{b}}$ \\
105 & $15.55 \pm 0.03^{\mathrm{a}}$ & $16.36 \pm 0.18^{\mathrm{a}}$ & $13.49 \pm 0.04^{\mathrm{a}}$ \\
112 & $18.00 \pm 0.10^{\mathrm{a}}$ & $18.09 \pm 0.14^{\mathrm{a}}$ & $17.55 \pm 0.08^{\mathrm{a}}$ \\
119 & $24.94 \pm 0.08^{\mathrm{a}}$ & $25.37 \pm 0.07^{\mathrm{a}}$ & $17.82 \pm 0.17^{\mathrm{b}}$ \\
126 & $27.50 \pm 0.10^{\mathrm{b}}$ & $36.49 \pm 0.12^{\mathrm{a}}$ & $19.08 \pm 0.21^{\mathrm{c}}$ \\
133 & $27.68 \pm 0.22^{\mathrm{b}}$ & $37.07 \pm 0.00^{\mathrm{a}}$ & $24.73 \pm 0.30^{\mathrm{b}}$ \\
140 & $29.94 \pm 0.10^{\mathrm{b}}$ & $39.02 \pm 0.11^{\mathrm{a}}$ & $28.33 \pm 0.20^{\mathrm{b}}$ \\
\hline
\end{tabular}

Values in the Table Oare Mean \pm standard deviation. Means with the same superscript in the row are not significantly different at $P \leq$ 0.05 using Duncan's Multiple Range Test 


\section{Table 04: $\quad$ Shoot height of $P$. nigrum cv. 'Kuching' plants inoculated with root knot nematodes.}

\begin{tabular}{|c|c|c|c|}
\hline \multirow{2}{*}{$\begin{array}{l}\text { Days after } \\
\text { inoculation }\end{array}$} & \multicolumn{3}{|c|}{ Shoot height (cm) } \\
\hline & Treatment 1 & Treatment 2 & Treatment 3 \\
\hline 7 & $4.89 \pm 0.55^{\mathrm{a}}$ & $5.33 \pm 0.25^{\mathrm{a}}$ & $6.03 \pm 0.19^{a}$ \\
\hline 14 & $5.33 \pm 0.20^{\mathrm{a}}$ & $7.20 \pm 0.26^{\mathrm{a}}$ & $7.87 \pm 0.07^{\mathrm{a}}$ \\
\hline 21 & $5.90 \pm 0.46^{\mathrm{b}}$ & $7.85 \pm 0.60^{\mathrm{ab}}$ & $9.53 \pm 0.74^{\mathrm{a}}$ \\
\hline 28 & $7.39 \pm 0.52^{b}$ & $12.34 \pm 0.66^{\mathrm{a}}$ & $8.65 \pm 0.47^{\mathrm{b}}$ \\
\hline 35 & $8.31 \pm 0.49^{b}$ & $11.39 \pm 0.33^{\mathrm{a}}$ & $8.67 \pm 0.72^{\mathrm{b}}$ \\
\hline 42 & $12.52 \pm 0.53^{b}$ & $17.90 \pm 0.41^{\mathrm{a}}$ & $12.40 \pm 0.53^{b}$ \\
\hline 49 & $13.71 \pm 0.60^{\mathrm{b}}$ & $21.44 \pm 0.62^{\mathrm{a}}$ & $15.79 \pm 0.66^{\mathrm{b}}$ \\
\hline 56 & $14.05 \pm 0.12^{\mathrm{b}}$ & $22.06 \pm 0.29^{\mathrm{a}}$ & $15.80 \pm 0.57^{b}$ \\
\hline 63 & $15.08 \pm 0.19^{b}$ & $25.84 \pm 0.04^{\mathrm{a}}$ & $16.40 \pm 0.05^{b}$ \\
\hline 70 & $17.24 \pm 0.09^{\mathrm{b}}$ & $26.06 \pm 0.09^{\mathrm{a}}$ & $18.13 \pm 0.05^{b}$ \\
\hline 77 & $17.39 \pm 0.18^{b}$ & $26.62 \pm 0.22^{\mathrm{a}}$ & $19.46 \pm 0.25^{b}$ \\
\hline 84 & $19.07 \pm 0.93^{b}$ & $27.34 \pm 0.57^{\mathrm{a}}$ & $21.44 \pm 0.45^{\mathrm{b}}$ \\
\hline 91 & $20.35 \pm 0.04^{b}$ & $27.76 \pm 0.01^{\mathrm{a}}$ & $21.62 \pm 0.05^{b}$ \\
\hline 98 & $24.35 \pm 0.05^{\mathrm{b}}$ & $30.62 \pm 0.07^{\mathrm{a}}$ & $24.90 \pm 0.02^{b}$ \\
\hline 105 & $27.81 \pm 0.04^{\mathrm{a}}$ & $31.45 \pm 0.03^{\mathrm{a}}$ & $29.01 \pm 0.06^{\mathrm{a}}$ \\
\hline 112 & $30.01 \pm 0.02^{\mathrm{a}}$ & $32.63 \pm 0.09^{\mathrm{a}}$ & $29.71 \pm 0.00^{\mathrm{a}}$ \\
\hline 119 & $34.01 \pm 0.10^{\mathrm{a}}$ & $35.37 \pm 0.05^{\mathrm{a}}$ & $33.64 \pm 0.05^{\mathrm{a}}$ \\
\hline 126 & $42.39 \pm 0.23^{\mathrm{a}}$ & $44.71 \pm 0.03^{\mathrm{a}}$ & $43.05 \pm 0.02^{\mathrm{a}}$ \\
\hline 133 & $45.17 \pm 0.06^{\mathrm{a}}$ & $45.91 \pm 0.23^{\mathrm{a}}$ & $43.93 \pm 0.11^{\mathrm{a}}$ \\
\hline 140 & $45.21 \pm 0.21^{\mathrm{a}}$ & $48.19 \pm 0.06^{\mathrm{a}}$ & $45.51 \pm 0.02^{\mathrm{a}}$ \\
\hline
\end{tabular}

Values in the Table Oare Mean \pm standard deviation. Means with the same superscript in the row are not significantly different at $P \leq$ 0.05 using Duncan's Multiple Range Test 
Table 05: $\quad$ Leaf area of new leaves of $P$. nigrum $\mathrm{cv}$. 'Kuching' plants inoculated with root knot nematodes

\begin{tabular}{|c|c|c|c|}
\hline \multirow{2}{*}{$\begin{array}{l}\text { Days after } \\
\text { inoculation }\end{array}$} & \multicolumn{3}{|c|}{ Leaf area of new leaves $(\mathrm{cm}) 2$} \\
\hline & Treatment 1 & Treatment 2 & Treatment 3 \\
\hline 7 & $17.69 \pm 0.59^{b}$ & $15.95 \pm 0.30^{\mathrm{b}}$ & $58.93 \pm 0.79^{\mathrm{a}}$ \\
\hline 14 & $19.58 \pm 0.60^{\mathrm{b}}$ & $23.28 \pm 0.39^{\mathrm{b}}$ & $40.59 \pm 0.77^{\mathrm{a}}$ \\
\hline 21 & $19.91 \pm 0.44^{\mathrm{c}}$ & $28.05 \pm 0.53^{\mathrm{b}}$ & $39.50 \pm 0.11^{\mathrm{a}}$ \\
\hline 28 & $23.01 \pm 0.63^{\mathrm{b}}$ & $32.99 \pm 0.85^{\mathrm{a}}$ & $23.28 \pm 0.70^{b}$ \\
\hline 35 & $24.67 \pm 0.40^{b}$ & $44.10 \pm 0.37^{\mathrm{a}}$ & $17.34 \pm 0.97^{\mathrm{b}}$ \\
\hline 42 & $32.29 \pm 0.34^{\mathrm{b}}$ & $59.42 \pm 0.11^{\mathrm{a}}$ & $18.05 \pm 0.33^{\mathrm{c}}$ \\
\hline 49 & $40.36 \pm 0.72^{b}$ & $66.24 \pm 0.28^{\mathrm{a}}$ & $21.44 \pm 0.68^{c}$ \\
\hline 56 & $44.21 \pm 0.41^{\mathrm{b}}$ & $64.81 \pm 0.23^{\mathrm{a}}$ & $36.40 \pm 0.15^{b}$ \\
\hline 63 & $44.91 \pm 0.35^{\mathrm{b}}$ & $60.86 \pm 0.59^{\mathrm{a}}$ & $40.18 \pm 0.58^{\mathrm{b}}$ \\
\hline 70 & $45.58 \pm 0.12^{b}$ & $61.74 \pm 0.71^{\mathrm{a}}$ & $43.21 \pm 0.69^{\mathrm{b}}$ \\
\hline 77 & $48.26 \pm 0.24^{b}$ & $68.83 \pm 0.11^{\mathrm{a}}$ & $44.15 \pm 0.25^{\mathrm{b}}$ \\
\hline 84 & $50.25 \pm 0.72^{\mathrm{b}}$ & $70.53 \pm 0.25^{\mathrm{a}}$ & $47.07 \pm 0.21^{\mathrm{b}}$ \\
\hline 91 & $51.66 \pm 0.87^{\mathrm{b}}$ & $72.04 \pm 0.10^{\mathrm{a}}$ & $50.20 \pm 0.18^{b}$ \\
\hline 98 & $52.70 \pm 0.175^{b}$ & $77.54 \pm 0.61^{\mathrm{a}}$ & $52.46 \pm 0.54^{b}$ \\
\hline 105 & $69.38 \pm 0.48^{\mathrm{a}}$ & $77.75 \pm 0.24^{\mathrm{a}}$ & $69.90 \pm 0.49^{\mathrm{a}}$ \\
\hline 112 & $71.09 \pm 0.83^{\mathrm{b}}$ & $84.34 \pm 0.73^{\mathrm{a}}$ & $80.01 \pm 0.12^{\mathrm{a}}$ \\
\hline 119 & $74.54 \pm 0.63^{b}$ & $86.04 \pm 0.10^{\mathrm{a}}$ & $85.63 \pm 0.69^{\mathrm{a}}$ \\
\hline 126 & $83.37 \pm 0.07^{\mathrm{a}}$ & $87.01 \pm 0.02^{\mathrm{a}}$ & $85.45 \pm 0.10^{\mathrm{a}}$ \\
\hline 133 & $84.16 \pm 0.10^{\mathrm{a}}$ & $87.56 \pm 0.08^{\mathrm{a}}$ & $87.07 \pm 0.05^{\mathrm{a}}$ \\
\hline 140 & $84.28 \pm 0.05^{c}$ & $96.34 \pm 0.12^{\mathrm{a}}$ & $89.93 \pm 0.03^{b}$ \\
\hline
\end{tabular}

Values in the Table Oare Mean \pm standard deviation. Means with the same superscript in the row are not significantly different at $P \leq$ 0.05 using Duncan's Multiple Range Test. 
Table 06: Number of new nodes of $P$. nigrum cv. 'Kuching' plants inoculated with root knot nematodes

\begin{tabular}{|c|c|c|c|}
\hline \multirow{2}{*}{$\begin{array}{l}\text { Days after } \\
\text { inoculation }\end{array}$} & \multicolumn{3}{|c|}{ Number of new nodes } \\
\hline & Treatment 1 & Treatment 2 & Treatment 3 \\
\hline 7 & $0.16 \pm 0.02^{\mathrm{a}}$ & $0.37 \pm 0.04^{\mathrm{a}}$ & $0.13 \pm 0.06^{\mathrm{a}}$ \\
\hline 14 & $0.201 \pm 0.09^{\mathrm{a}}$ & $0.58 \pm 0.06^{\mathrm{a}}$ & $0.53 \pm 0.03^{\mathrm{a}}$ \\
\hline 21 & $0.29 \pm 0.06^{\mathrm{a}}$ & $1.37 \pm 0.02^{\mathrm{a}}$ & $1.26 \pm 0.02^{\mathrm{a}}$ \\
\hline 28 & $0.57 \pm 0.06^{\mathrm{b}}$ & $3.53 \pm 0.02^{\mathrm{a}}$ & $2.01 \pm 0.03^{\mathrm{ab}}$ \\
\hline 35 & $1.81 \pm 0.08^{\mathrm{b}}$ & $5.44 \pm 0.01^{\mathrm{a}}$ & $5.38 \pm 0.03^{\mathrm{a}}$ \\
\hline 42 & $2.47 \pm 0.06^{\mathrm{b}}$ & $6.24 \pm 0.03^{\mathrm{a}}$ & $7.45 \pm 0.02^{\mathrm{a}}$ \\
\hline 49 & $4.01 \pm 0.02^{\mathrm{b}}$ & $8.18 \pm 0.01^{\mathrm{a}}$ & $8.10 \pm 0.05^{\mathrm{a}}$ \\
\hline 56 & $5.33 \pm 0.54^{\mathrm{b}}$ & $8.57 \pm 0.06^{\mathrm{a}}$ & $8.42 \pm 0.09^{\mathrm{a}}$ \\
\hline 63 & $5.83 \pm 0.08^{b}$ & $9.88 \pm 0.05^{\mathrm{a}}$ & $9.55 \pm 0.09^{\mathrm{a}}$ \\
\hline 70 & $6.34 \pm 0.02^{\mathrm{b}}$ & $10.57 \pm 0.05^{\mathrm{a}}$ & $9.72 \pm 0.03^{\mathrm{a}}$ \\
\hline 77 & $7.50 \pm 0.02^{\mathrm{b}}$ & $10.76 \pm 0.09^{\mathrm{a}}$ & $9.75 \pm 0.04^{\mathrm{ab}}$ \\
\hline 84 & $9.24 \pm 0.04^{b}$ & $13.12 \pm 0.05^{\mathrm{a}}$ & $10.04 \pm 0.01^{\mathrm{b}}$ \\
\hline 91 & $10.21 \pm 0.05^{\mathrm{b}}$ & $14.65 \pm 0.09^{\mathrm{a}}$ & $10.00 \pm 0.02^{b}$ \\
\hline 98 & $14.50 \pm 0.10^{\mathrm{ab}}$ & $17.55 \pm 0.04^{\mathrm{a}}$ & $10.84 \pm 0.04^{b}$ \\
\hline 105 & $15.12 \pm 0.03^{\mathrm{a}}$ & $17.83 \pm 0.07^{\mathrm{a}}$ & $15.09 \pm 0.08^{\mathrm{a}}$ \\
\hline 112 & $19.63 \pm 0.05^{\mathrm{a}}$ & $21.39 \pm 0.09^{\mathrm{a}}$ & $19.04 \pm 0.08^{\mathrm{a}}$ \\
\hline 119 & $20.88 \pm 0.08^{\mathrm{a}}$ & $22.97 \pm 0.07^{\mathrm{a}}$ & $20.49 \pm 0.05^{\mathrm{a}}$ \\
\hline 126 & $22.69 \pm 0.09^{a}$ & $23.69 \pm 0.51^{\mathrm{a}}$ & $23.04 \pm 0.50^{\mathrm{a}}$ \\
\hline 133 & $25.55 \pm 0.21^{b}$ & $32.55 \pm 0.83^{\mathrm{a}}$ & $28.52 \pm 0.06^{\mathrm{ab}}$ \\
\hline 140 & $27.71 \pm 0.12^{b}$ & $38.97 \pm 0.81^{\mathrm{a}}$ & $32.09 \pm 0.32^{\mathrm{ab}}$ \\
\hline
\end{tabular}

Values in the Table Oare Mean \pm standard deviation. Means with the same superscript in the row are not significantly different at $P \leq$ 0.05 using Duncan's Multiple Range Test

Effect on the root system of $P$. nigrum $c v$. 'Kuching' plants inoculated with Root Knot Nematodes

Hoagland solution only $\left(\mathrm{T}_{1}\right)$ : Roots of $P$. nigrum cv. 'Kuching' plants irrigated with Hoagland solution only $\left(\mathrm{T}_{1}\right)$ were the most RKN-infested (Fig.01.) compared to roots from Hoagland solution supplemented with potassium silicate $\left(\mathrm{T}_{2}\right)$ and Hoagland solution supplemented with salicylic acid $\left(\mathrm{T}_{3}\right)$ (Fig.02. and 03., respectively). In $\mathrm{T}_{1}$, rotten root and broken root galls were observed in addition to damaged lower root section. Additionally, root tips and root hairs of most roots were 'colonized' by many small root galls (Fig.01.).

Hoagland solution $+0.005 \mathrm{mM}$ potassium silicate solution $\left(T_{2}\right)$ : Roots from $P$. nigrum cv. 'Kuching' plants irrigated with Hoagland 
solution supplemented with potassium silicate $\left(\mathrm{T}_{2}\right)$ produced the fewest number of root galls, as shown in Fig.02.

Hoagland solution $+2 \mathrm{mM}$ salicylic acid solution $\left(T_{3}\right)$ : Roots of $P$. nigrum cv. 'Kuching' plants irrigated with Hoagland solution supplemented with salicylic acid $\left(\mathrm{T}_{3}\right)$ had a higher number of infested roots coupled with bigger root galls (Fig.03.) compared to the roots of $P$. nigrum cv.
'Kuching' plants irrigated with Hoagland solution supplemented with potassium silicate $\left(\mathrm{T}_{2}\right)$. Root galls of the former were observed even at the point of attachment of the primary roots to the stems, others formed at the point of attachment of tertiary roots to secondary roots (Fig.03.), and the majority of the root galls were observed on tertiary roots.

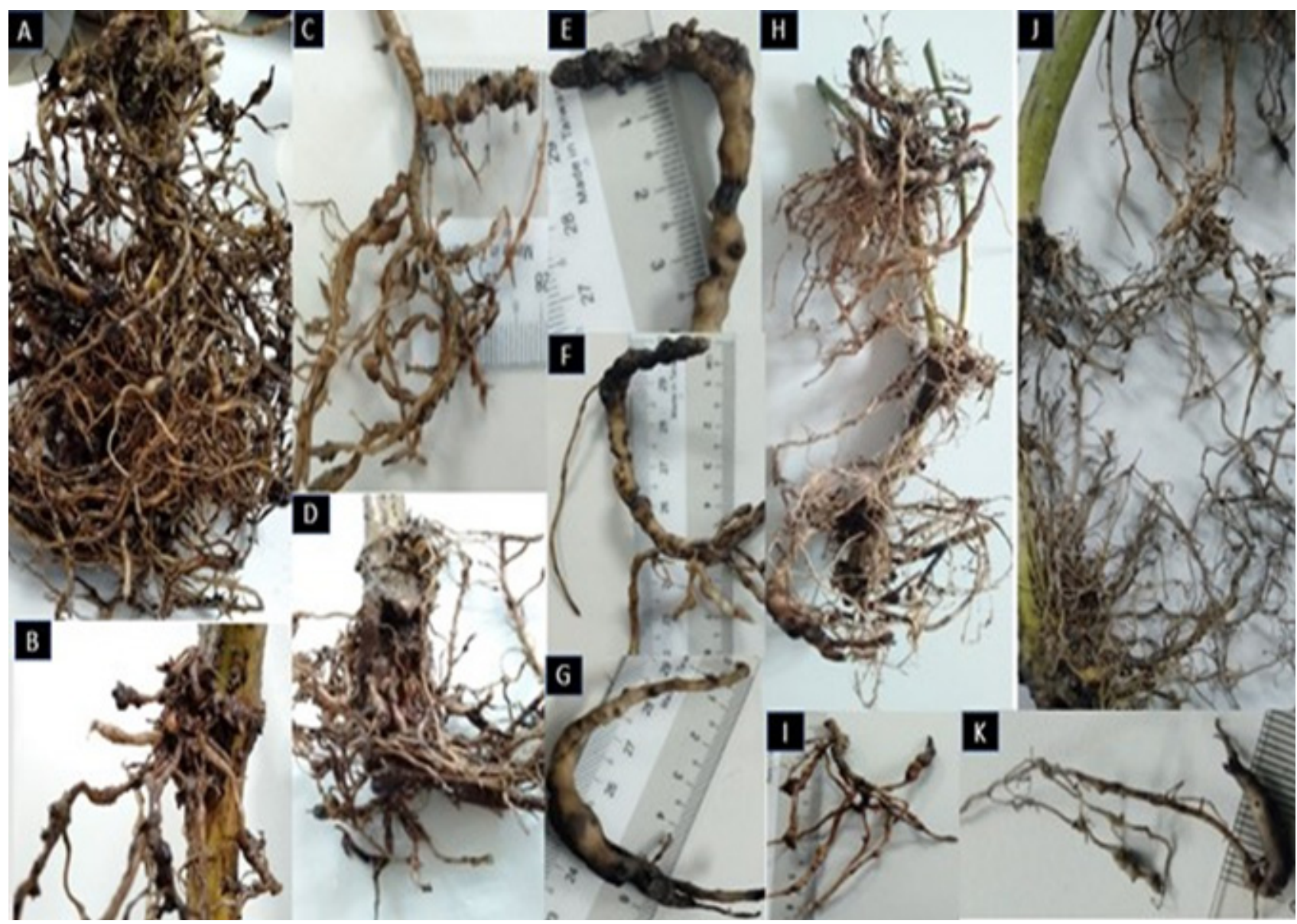

Figure 01: Heavily galled roots of RKN-inoculated Piper nigrum L. var Kuching plants irrigated with Hoagland solution only $\left(T_{1}\right)$. Root galls distributed on quaternary and tertiary roots (A), primary roots (B), secondary roots $(C)$, at the point of attachment of the primary root to the stem (D). Rotten and broken root galls were observed $(E, F)$, and, in some roots, the lower section was damaged $(G)$. Root tips and root hairs of most roots were 'colonized' by many root galls $(\mathrm{H}, \mathrm{I}, \mathrm{J}, \mathrm{K})$. 


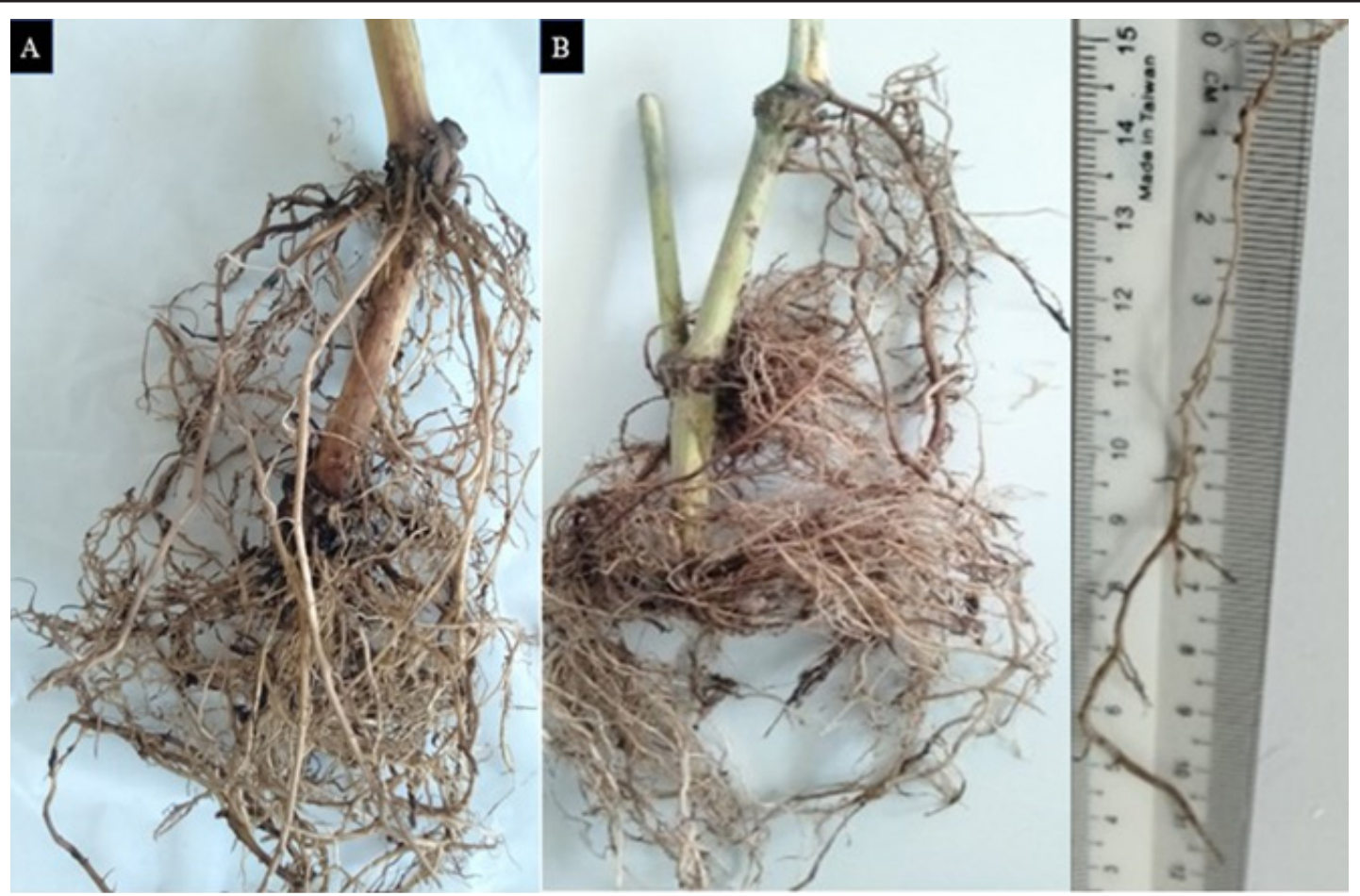

Figure 02: Uninoculated roots (A) and RKN-inoculated roots (B) of Piper nigrum L. var Kuching plants irrigated with Hoagland solution supplemented with potassium silicate solution $\left(\mathrm{T}_{2}\right)$.

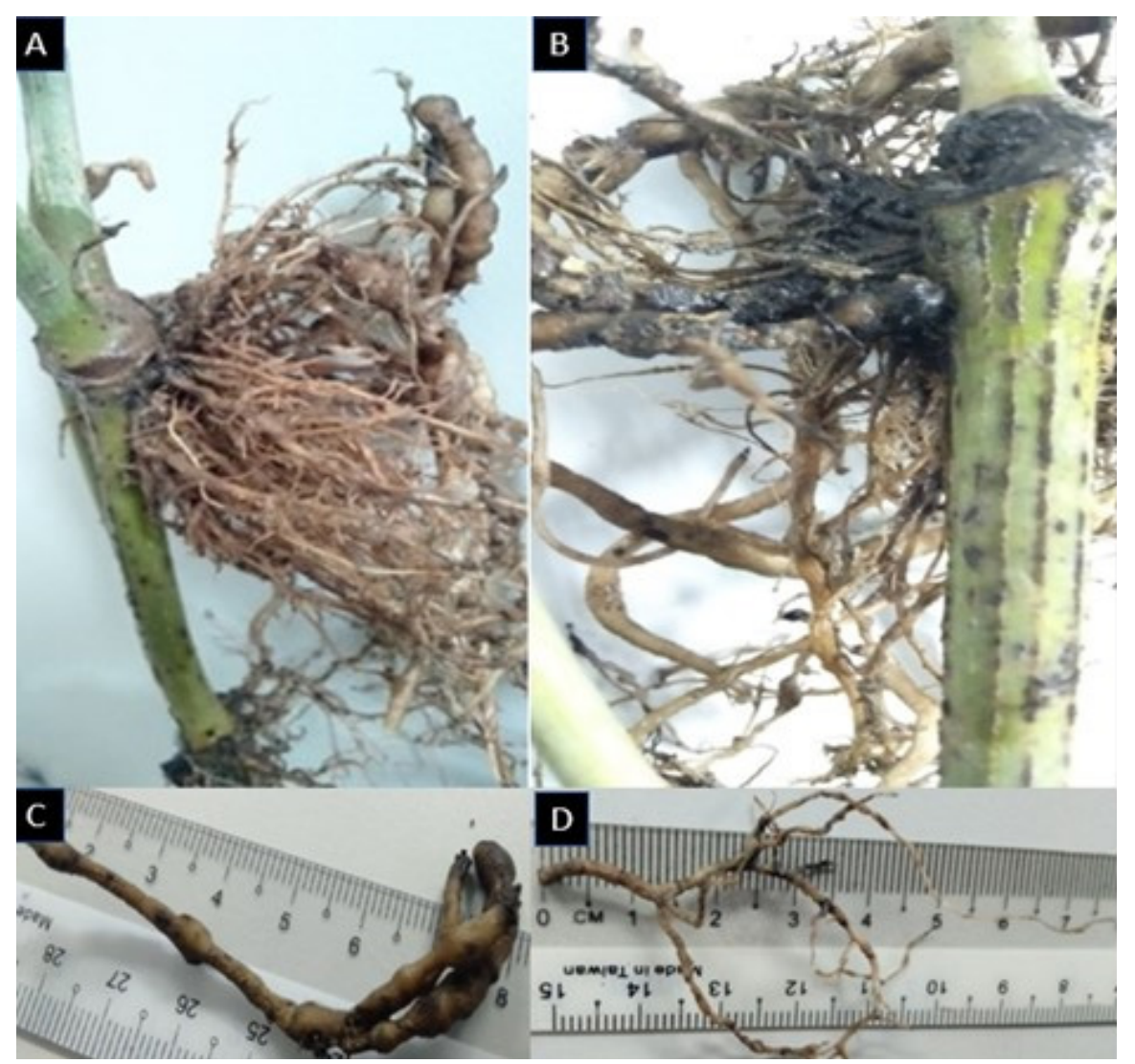

Figure 03: Distribution of galls on different roots of RKN-inoculated Piper nigrum L. var Kuching plants irrigated with Hoagland solution supplemented with salicylic acid solution $\left(T_{3}\right)$. Big root galls formed at the root tip (A), at the point of attachment of the primary root to the stem (B), at the point of attachment of the tertiary root to the secondary root (C). Majority of the root galls on tertiary roots (D). 
Detection of Superoxide anion and Hydrogen peroxide in leaves of $P$. nigrum cv. 'Kuching' plants inoculated with Root Knot Nematodes

Production of superoxide anions $\left(\mathrm{O}_{2}^{\bullet-}\right)$ and hydrogen peroxide $\left(\mathrm{H}_{2} \mathrm{O}_{2}\right)$ in leaves of $P$. nigrum cv. 'Kuching' plants inoculated with RKN generally increased as the number of days after inoculation (dai) increased from 0 to 25, as shown in Figs.04 and 05., respectively. Considerable differences in accumulation of $\mathrm{O}_{2} \bullet$ - among the investigated treatments were evident at 10 dai, with the strongest staining intensity in leaves of Hoagland solution only $\left(\mathrm{T}_{1}\right)$ followed by Hoagland solution supplemented with salicylic acid $\left(\mathrm{T}_{3}\right)$ and then by Hoagland solution supplemented with potassium silicate
$\left(\mathrm{T}_{2}\right)$ i.e. $\mathrm{T}_{1}>\mathrm{T}_{3}>\mathrm{T}_{2}$. Overall, Hoagland solution supplemented with potassium silicate solution produced the least $\mathrm{O}_{2} \bullet$-, whereas Hoagland solution supplemented with salicylic acid produced the highest $\mathrm{O}_{2} \cdot-$, as shown in Fig.04. On the other hand, considerable differences in the 3,3'diaminobenzidine (DAB) staining intensity among the treatments were manifested as early as 05 dai, with the strongest detection in leaves of Hoagland solution supplemented with salicylic acid $\left(\mathrm{T}_{3}\right)$ followed by Hoagland solution only $\left(\mathrm{T}_{1}\right)$ i.e. $\mathrm{T}_{3}>\mathrm{T}_{1}>\mathrm{T}_{2}$. Once again, Hoagland solution supplemented with potassium silicate solution $\left(\mathrm{T}_{2}\right)$ produced the least $\mathrm{H}_{2} \mathrm{O}_{2}$. Traces of $\mathrm{O}_{2} \cdot$ - and $\mathrm{H}_{2} \mathrm{O}_{2}$ were detected at 0 dai and in some leaves of the control samples at several dai, as shown in Figs.04 and 05., respectively.

\section{Before inoculation (0 dai)}
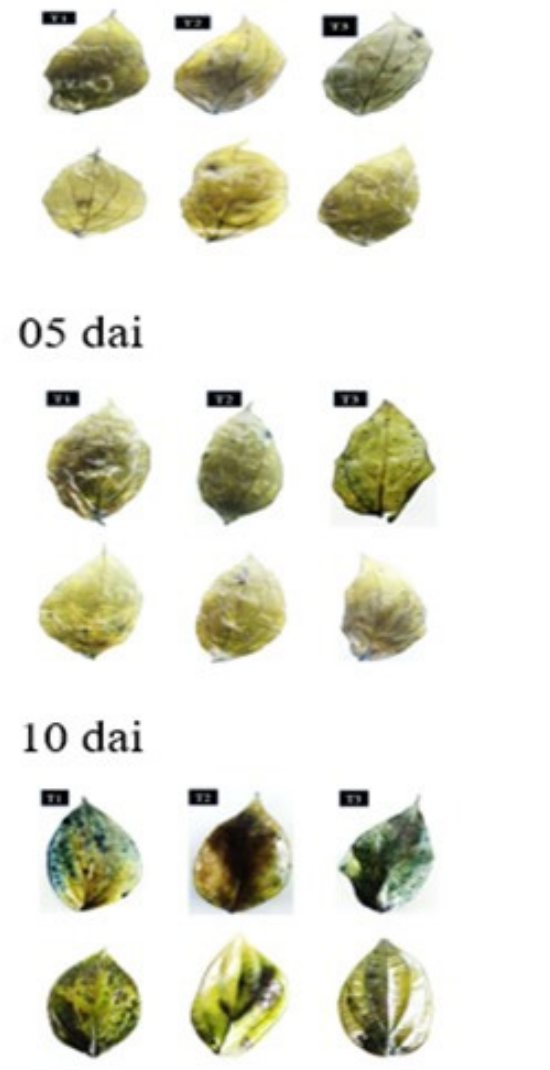
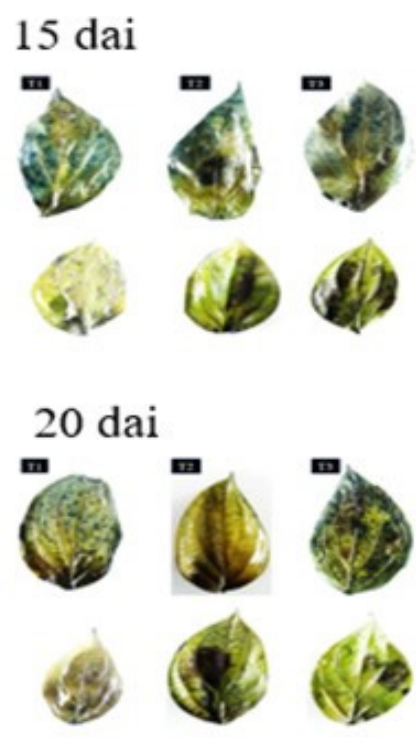

25 dai

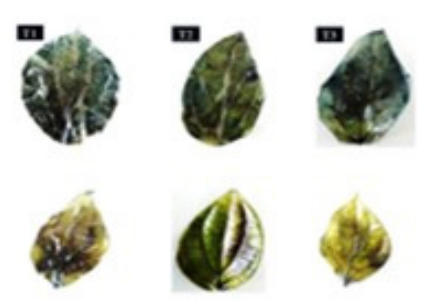

Figure 04: Superoxide anion assay of leaves of Piper nigrum $L$. var Kuching plants at different dai (days after inoculation). Leaves on the second row of each dai are control leaves for the corresponding treatment. One representative leaf is shown for each treatment and control, on each dai. 

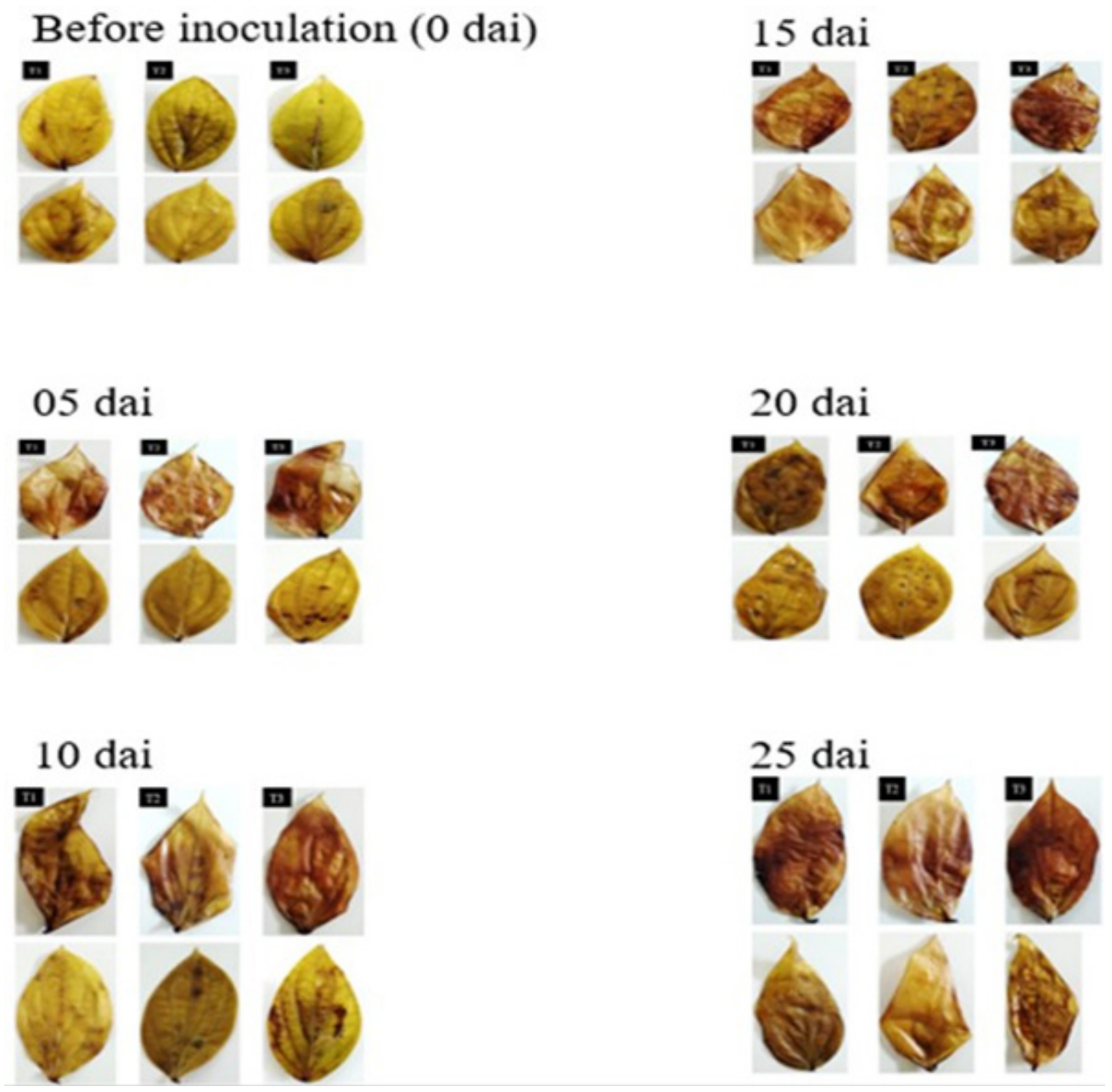

Figure 05: Hydrogen peroxide assay of leaves of Piper nigrum $L$. var Kuching plants at different dai (days after inoculation). Leaves on the second row of each dai are control leaves for the corresponding treatment. One representative leaf is shown for each treatment and control, on each dai.

\section{DISCUSSION}

Foliar Symptoms of Infection exhibited by P. nigrum cv. 'Kuching' plants inoculated with Root Knot Nematodes

Root knot nematodes (RKN) infection is accompanied by nutrient partitioning in the host plant which manifests as leaf yellowing, wilting even when the soil is adequately moist, nutritional deficiencies, stunted growth, among other symptoms (Mhatre et al., 2020). The nonuniform leaf yellowing and plant wilting even in the presence of adequate soil moisture, have also been observed by Trinh (2010) in leaves of $P$. nigrum infested with $M$. incognita. Leaf yellowing as a result of Meloidogyne species infection in $P$. nigrum fields has also been reported in previous studies (Phong et al., 2020).
Present findings indicate that the total number of P. nigrum cv. 'Kuching' plants exhibiting foliar symptoms of RKN infection increased with time in all treatments (Table 01 ). This result agrees with Trinh (2010) in which the proportion of yellow leaves in $M$. incognita and $F$. solani-inoculated black pepper plants increased as the period after inoculation increased. Foliar symptoms of RKN infection were first observed and was significantly the highest in plants irrigated with Hoagland solution only $\left(\mathrm{T}_{1}\right)$ followed by Hoagland solution supplemented with salicylic acid $\left(\mathrm{T}_{3}\right)$ (Table 01). This was due to reduced soil nutrient absorption owing to the majority of the root hairs and root tips being 'colonized' by many root galls, as discussed in the following sections of this report and shown in Figs.01 and 03. This observation suggests that $\mathrm{T}_{1}$ and $\mathrm{T}_{3}$ did not reduce root galling and with our experimental conditions, non- 
uniform yellowing of leaves and wilting even in the presence of adequate soil moisture was prevalent in black pepper plants. These effects were most pronounced at 109 dai, when all the inoculated plants in the experiment showed significant results over the uninoculated plants! Above ground symptoms of RKN infection e.g. wilting during the hottest times of the day reduce the water and nutrient absorption ability of plants, hence nutrient deficiencies accompanied by poor plant growth (Decraemer and Hunt, 2006).

As expected, the shoot system of uninoculated plants appeared healthy and uniformly green up to 102 dai. Infection symptoms in uninoculated plants slowly started manifesting at 109 dai and such symptomatic plants remained very few even by the end of the experiment, compared to inoculated plants in all other treatments. This observation is supported by Trinh (2010)'s findings for which the proportion of yellow black pepper leaves was lowest in the uninoculated plants, with only $\sim 8 \%$ of yellow leaves at the end of the experiment. Presence of some infection symptoms in the leaves of uninoculated plants suggests that the soil/greenhouse could have been contaminated with another pathogen (not identified in the present study) from 109 dai up to 144 dai (end of the experiment).

\section{Effect of Root Knot Nematodes on the aerial growth of $P$. nigrum cv. 'Kuching' plants irrigated with different Treatment Compositions}

In the present study, RKN impacted on shoot growth differently under different treatments. Highest shoot growth parameters were observed in plants irrigated with Hoagland solution supplemented with potassium silicate $\left(\mathrm{T}_{2}\right)$, followed by Hoagland solution supplemented with salicylic acid $\left(\mathrm{T}_{3}\right)$ whereas the least shoot growth was generally observed in plants irrigated with Hoagland solution only $\left(\mathrm{T}_{1}\right)$ (Tables 02, 03, 04, 05 and 06). The significantly lowest shoot growth parameters of $P$. nigrum cv. 'Kuching' plants irrigated with Hoagland solution only are attributed to heavy root colonization by RKN (Fig.01.) which not only impairs efficient nutrient and water absorption from the soil but also impedes their movement to the upper parts of the plant hence poor shoot growth (Kayani et al., 2017).

Present results for which supplementation of Hoagland solution with $2 \mathrm{mM}$ salicylic acid solution $\left(\mathrm{T}_{3}\right)$ in RKN-inoculated experimental plants generally produced better shoot criteria than those plants irrigated with Hoagland solution only $\left(\mathrm{T}_{1}\right)$ corroborate with previous findings (Vicente and Plasencia, 2011). The significantly lower shoot growth criteria of inoculated plants irrigated with $\mathrm{T}_{3}$ than inoculated plants irrigated with $T_{2}$ in the present study could be arising from the $2 \mathrm{mM}$ SA-associated toxicity towards experimental plants, owing to the long experimental duration. This hypothesis is backed by Vicente and Plasencia (2011) who emphasized that success of exogenous SA in alleviating biotic stress depends on the SA concentration used, duration of exposure, the particular cause of biotic stress (e.g. fungal, bacterial, parasite, etc.), plant variety in question and its developmental stage. Moreover, no studies on the use of exogenous SA to reduce root galling in $P$. nigrum cv. 'plants could be traced from the literature available.

P. nigrum cv. 'Kuching' plants irrigated with Hoagland solution supplemented with potassium silicate $\left(\mathrm{T}_{2}\right)$ produced the highest aerial growth parameters throughout the experimental period. Present findings are supported by Ahmed et al. (2013) in which the increasing concentrations of potassium silicate applied facilitated higher plant growth, chlorophyll content and percentage fruit set than salicylic acid treatments. In a greenhouse experiment, application of potassium silicate on cucumber plant cv. 'Hybrid Alpha' improved the shoot growth parameters i.e. plant length, number of leaves per plant, total plant fresh weight and shoot dry weight, compared to nonsilicon treated plants (El-sherif et al., 2016).

From the current study, the first spike was observed in P. nigrum cv. 'Kuching' plants irrigated with Hoagland solution supplemented with potassium silicate $\left(\mathrm{T}_{2}\right)$, indicating that $\mathrm{Si}$ has an effect on flowering and fruit production as highlighted by Dehghanipoodeh et al. (2015). Silicon-deprived plants can reduce growth, making them more prone to both biotic and abiotic stresses (Laane, 2018). 
Additional potassium may have contributed to the significantly highest shoot growth parameters observed in $\mathrm{T}_{2}$ plants in this study. Also the damage caused by RKN may be reduced with the increased amount of potassium supplied to the host plant; as demonstrated by Bakir (1952) where growth of lima bean plants inoculated with M. incognita increased with increased amounts of potassium supplied to the plants. From the present study therefore, RKN impacted on the shoot growth parameters of $P$. nigrum cv. 'Kuching' plants differently in different treatments; better shoot growth was promoted in spite of RKN presence in potassium silicate amendments, than with other nutrient compositions.

\section{Effect on the root system of $P$. nigrum $c v$. 'Kuching' plants inoculated with Root Knot Nematodes}

According to Baidoo et al. (2014), root galling, loss of root hairs, and ultimately susceptibility to other root infections are among the most prominent root symptoms of RKN infestation. From the present study, roots of $P$. nigrum cv. 'Kuching' plants irrigated with Hoagland solution only $\left(\mathrm{T}_{1}\right)$ were the most RKN-infested (Fig.01.) followed by roots from plants irrigated with Hoagland solution supplemented with salicylic acid $\left(\mathrm{T}_{3}\right)$ (Fig.03.). Rotten and broken root galls were observed in $\mathrm{T}_{1}$ roots in addition to damaged root tips. Root tips and root hairs of most roots were 'colonized' by many small root galls (Fig.01.). After penetrating the host, RKN interferes with nutrient and water uptake of the plant resulting in root malformations, typical knots and in severe cases root galls formed on the invaded root break, causing root damage, resulting in a rot (Moens et al., 2009). This gives opportunity to pathogenic fungi such as $P$. capsici and bacteria to colonize and accelerate root decay (Megir and Paulus, 2011). This explains the damaged root tips, rotten and damaged root galls observed in $\mathrm{T}_{1}$ in addition to heavy colonization of root hairs with root galls.

In this study, irrigation of P. nigrum cv. 'Kuching' plants with Hoagland solution supplemented with salicylic acid $\left(\mathrm{T}_{3}\right)$ presented many infested roots coupled with bigger root galls (Fig.03.) compared to the roots of plants irrigated with Hoagland solution supplemented with potassium silicate $\left(T_{2}\right)$. Root galls of the former were observed even at the point of attachment of the primary roots to the stem. Present results are partly supported by Moslemi et al. (2016) where application of $50 \mu \mathrm{M}$ SA on tomato (Solanum lycopersicum) seedlings through soil drenching only reduced the number of root galls to a lesser extent; SA effectively lowered $M$. javanica root infestation only when it was applied through seed priming. As few studies have reported positive results of SA application through soil drenching, its potential in halting the process of giant cell and/ or root gall formation in $\mathrm{RKN}$-inoculated plant roots still merits further investigation.

From the present study, roots of $P$. nigrum cv. 'Kuching' plants irrigated with Hoagland solution supplemented with potassium silicate $\left(\mathrm{T}_{2}\right)$ presented root systems with a few root galls (Fig.02.) compared to other nutrient compositions. It has been evidenced that silicon (Si) negatively impacts on $\mathrm{RKN}$ reproduction and development in plant roots (Mattei et al., 2016; Zhan et al., 2018). Application of potassium silicate can reduce $M$. incognita infestation in which there are less numbers of root galls, egg masses, reproduction rate, and final population density as shown with cucumber plants treated with potassium silicate (El-sherif et al., 2016). Similarly, silicon application has a potential to reduce the population density of $M$. javanica as evidenced in soybean, common bean and rice (Mattei et al., 2016).

Important to note, potassium might also have contributed to the very few root galls observed in $T_{2}$ plants in the current study. Nourishment of plants with adequate potassium not only increases their pathogen penetration resistance but also impedes pathogen development (Huber and Arny, 1985; Santos et al., 1981). As the plants irrigated with potassium silicate $\left(\mathrm{T}_{2}\right)$ suffered the least RKN infestation, present findings therefore, indicate that soil drenching with potassium silicate is a promising viable tool in reducing root galling caused by Meloidogyne species in black pepper ( $P$. nigrum) fields heavily infested with root knot nematodes. 
Detection of Superoxide anion and Hydrogen peroxide in leaves of $P$. nigrum cv. 'Kuching' plants inoculated with Root Knot Nematodes

Plant stress causes oxidative damage that manifests as increased production of reactive oxygen species (ROS) by the cells, whose role in plant defense is crucial (Sharma et al., 2012). ROS levels increase during pathogen feeding (Santamaria et al., 2018) and this supports present findings for which $\mathrm{O}_{2} \cdot$ - accumulation in leaves of inoculated plants generally increased as the number of days after inoculation increased (Fig.04.), synergizing with the increased root galling. The strong staining intensity in leaves of $P$. nigrum cv. 'Kuching' plants irrigated with Hoagland solution supplemented with salicylic acid $\left(\mathrm{T}_{3}\right)$ and in Hoagland solution only $\left(\mathrm{T}_{1}\right)$ in this study, reflect the increased $\mathrm{O}_{2} \bullet$ - accumulation and defense reaction from plants as a result of successful RKN root colonization, evidenced by the high root galling observed in Fig.01. and 03. Pepper plants irrigated with Hoagland solution supplemented with salicylic acid $\left(\mathrm{T}_{3}\right)$ displayed strong staining intensity for $\mathrm{O}_{2} \bullet-$ accumulation, which could be mainly attributed by the presence of salicylic acid. Salicylic acid is known to mediate an increase in ROS production in stressed plants (Sharma et al., 2012). Sometimes, exogenous SA can induce an increase in the ROS concentration of plants even in the absence of a biotic stressor (Wang et al., 2011)!

Hoagland solution supplemented with potassium silicate solution $\left(\mathrm{T}_{2}\right)$ produced the least $\mathrm{O}_{2} \cdot$ in leaves of $P$. nigrum cv. 'Kuching' plants inoculated with RKN (Fig.04.), owing to the least root galling (Fig.02.) due to the protective role of silicon against RKN (Zhan et al., 2018) which could have impeded most RKN from successful root colonization.

In the present study, considerable differences in the DAB staining intensity amongst the investigated treatment compositions were evident as early as 05 dai, with the strongest detection in leaves of Hoagland solution supplemented with salicylic acid $\left(\mathrm{T}_{3}\right)$ followed by Hoagland solution only $\left(\mathrm{T}_{1}\right)$ i.e. $\mathrm{T}_{3}>\mathrm{T}_{1}>\mathrm{T}_{2}$ (Fig.05.). The present study thus indicates that the high RKN infestation evident in the root system of $\mathrm{T}_{3}$ and $\mathrm{T}_{1}$ plants is responsible for their high $\mathrm{H}_{2} \mathrm{O}_{2}$ accumulation. In line with the above argument, the weak staining intensity of $\mathrm{T}_{2}$ (Hoagland solution supplemented with potassium silicate solution) plants in the present study further verifies the protective role of potassium silicate solution against RKN, which was evidenced with low oxidative stress (least $\mathrm{O}_{2} \bullet$ - and $\mathrm{H}_{2} \mathrm{O}_{2}$ accumulation).

Traces of $\mathrm{O}_{2} \cdot$ - and $\mathrm{H}_{2} \mathrm{O}_{2}$ were detected at 0 dai and in the control leaves at several dai (Fig.04. and 05. respectively). This supports that ROS are consistently produced in lower quantities as byproducts during normal aerobic metabolism in plants (Ali et al., 2018; Charles et al., 1997). In the present study, expression of oxidative stress in the tested plants in the form of $\mathrm{H}_{2} \mathrm{O}_{2}$ was earlier and stronger staining intensity than as $\mathrm{O}_{2} \bullet-$. This may associated to the high stability of $\mathrm{H}_{2} \mathrm{O}_{2}$, which is regarded as the most sTable 0ROS. In addition to its less reactivity, high diffusion rate across the cell membrane to distant locations from its production sites is also a recognisable feature of $\mathrm{H}_{2} \mathrm{O}_{2}$ (Nicholas and Dominique, 2019). On the other hand, $\mathrm{O}_{2} \bullet$ - are not only short-lived i.e. their production is followed by a rapid redox reaction to $\mathrm{H}_{2} \mathrm{O}_{2}$ but are also poorly membrane permeable (Nicholas and Dominique, 2019).

\section{CONCLUSIONS}

Results of the present study support the concept that potassium silicate application through soil drenching not only reduces root galling caused by RKN in $P$. nigrum cv. 'Kuching' plants but also promotes better shoot growth. The NBT and $\mathrm{DAB}$ histochemical staining assays revealed increasing oxidative stress with time in $P$. nigrum cv. 'Kuching' leaves resulting from RKN infestation of the root system. Future research needs to address the effects of potassium silicate on RKN development in black pepper plants under field conditions, with less focus on greenhouse studies.

\section{Conflicts of Interest}

The authors declare no conflicts of interest. 


\section{ACKNOWLEDGEMENT}

The authors thank the Islamic Development Bank (IsDB) for awarding Babirye Khadijah a Masters scholarship to study at Universiti Putra
Malaysia. This research was funded by Putra Grant GP-IPB/2018/9557607 from Universiti Putra Malaysia.

\section{REFERENCES}

Ahmed, F.F. Mansour, A.E.M. Mohamed, A.Y. Mostafa, E.A.M. and Ashour, N.E (2013). Using silicon and salicylic acid for promoting production of Hindy Bisinnara mango trees grown under sandy soil. Middle East Journal of Agricultural Research. 2(2): 51-55.

Ali, M. Cheng, Z. Ahmad, H. and Hayat, S (2018). Reactive oxygen species (ROS) as defenses against a broad range of plant fungal infections and case study on ROS employed by crops against Verticillium dahliae wilts. Journal of Plant Interactions. 13(1): 353-363.https://doi.org /10.1080/17429145.2018.1484188

Ashwin, N.M.R. Barnabas, L. Ramesh, S.A. Malathi, P. Viswanathan, R. Masi, A. Agrawal, G.K. and Rakwal, R (2018). CfPDIP1, a novel secreted protein of Colletotrichum falcatum, elicits defense responses in sugarcane and triggers hypersensitive response in tobacco. Applied Microbiology and Biotechnology. 102: 1-21. doi: https://doi.org/10.1007/ s00253-018-9009-2

Baidoo, R. Stamps, R.H. and Crow, W.T (2014). Pathogenicity and management of Meloidogyne incognita on Pittosporum tobira in Florida. Journal of Nematology. 46(2): 135-136.

Bakir, A. O. (1952). Potassium nutrition of the host in relation to infection by a root knot nematode Meloidogyne incognita. Proceedings of the Helminthological society of Washington, 19(2), 99104.

Charles, S.B. Ian, R.B. Mark, H.R.B. and John, W.M (1997). Localisation of hydrogen peroxide accumulation during the hypersensitive reaction of lettuce cells to Pseudomonas Syringae pv phaseolicola. The Plant Cell. 9: 209-221.https://doi.org/10.1105/tpc.9.2.209

Decraemer, W. and Hunt, D (2006). Structure and classification. In: Plant Nematology. (Perry, R. and Moens, M. Eds.). CAB International, Wallingford. 3-32.

Dehghanipoodeh, S. Ghobadi, C. Benincasa, B. Gheysari, M. and Bidabadi, S.S (2015). Effects of potassium silicate and nanosilica on quantitative and qualitative characteristics of a commercial strawberry (fragaria $\times$ ananassa cv. "camarosa"). Journal of Plant Nutrition. 39(4): 502-507. https://doi.org/10.1080/01904167.2015.1086789

De Swart, E.A.M. Groenwold, R. Kanne, H.J. Stam, P. Marcelis, L.F.M. and Voorrips, R.E (2004). Non-destructive estimation of leaf area for different plant ages and accessions of Capsicum annuum L. Journal of Horticultural Science and Biotechnology. 79(5): 764-770. https://doi.or $\mathrm{g} / 10.1080 / 14620316.2004 .11511840$

El-Sherif, A.G. Gad, S.B. and Saadoon, S.M (2016). Impact of Potassium Silicate Application on Meloidogyne incognita Infecting Cucumber Plant under Greenhouse Conditions. Asian Journal of Nematology. 5(1): 1-7. https://doi.org/10.3923/ajn.2016.1.7

Huber, D.M. and Arny, D.C (1985). Interactions of potassium with plant disease. In: Potassium in agriculture. (Munson, R.D. Ed.). Madison, New York, USA. 467-488. 
Izzah, A.H. and Wan Asrina, W.Y. (2019). Black Pepper in Malaysia: An Overview and Future Prospects. Agricultural Reviews. 40(4): 296-302.https://doi.org/10.18805/ag.R-129.

Kayani, M.Z. Mukhtar, T. and Hussain, M.A(2017). Effects of southern root knot nematode population densities and plant age on growth and yield parameters of cucumber. Crop Protection. 92: 207212. http://dx.doi.org/10.1016/j.cropro.2016.09.007

Khan, F. Banday, F. Narayan, S. and Bhat, S (2016). Use of Models as Non-destructive Method for Leaf Area Estimation in Horticultural Crops. IRA-International Journal of Applied Sciences. 4(1). doi: http://dx.doi.org/10.21013/jas.v4.n1.p19.

Kumar, D. Yusuf, M.A. Singh, P. Sardar, M. and Sarin, N.B (2014). Histochemical Detection of Superoxide and $\mathrm{H}_{2} \mathrm{O}_{2}$ Accumulation in Brassica juncea Seedlings. Bio-protocol. 4(8). https:// doi.org/10.21769/BioProtoc. 1108

Laane, H. (2018). The Effects of Foliar Sprays with Different Silicon Compounds. Plants, $7(2), 45$. https://doi.org/10.3390/plants7020045

Lau, E.T. Hwang, S.S. Lily, E. and Paulus, A.D (2012). Cloning and characterization of Resistance Gene Analogues (RGAs) from Piper nigrum L. cv. Semongok Aman and Piper colubrinum Link. APCBEE Procedia. 4: 215 - 219. https://doi.org/10.1016/j.apcbee.2012.11.036

Mattei, D. Dias-Arieira, C.R. Lopes, A.P.M. and Miamoto, A (2016). Influence of Rocksil®, Silifort ${ }^{\circledR}$ and Wollastonite on Penetration and Development of Meloidogyne javanica in Poaceae and Fabaceae. Journal of Phytopathology. 165(2): 91-97. https://doi.org/10.1111/jph.12540

Matthew, C.E. and Olubukola, O.B. (2019). The impact of microbes in the orchestration of plants' resistance to biotic stress: A disease management approach. Applied Microbiology and Biotechnology. 103: 9-25. https://doi.org/10.1007/s00253-018-9433-3

Megir, G. and Paulus, A.D. (2011). Pepper Production Technology in Malaysia. (Fong L.K. and Liang, S.S. Eds.). Malaysian Pepper Board, Sarawak, Malaysia.

Mhatre, P.H. Santhosh, J.E. Gautam, C. Rashid, P. Agisha, V.N. Sirisha, T. and Nagesh, M (2020). Isolation and characterization of Pasteuria parasitizing root-knot nematode, Meloidogyne incognita, from black pepper fields in India. Egyptian Journal of Biological Pest Control. 30, 97.

Mitkowski, N.A. and Abawi, G.S. (2003). Root-knot nematodes. The Plant Health Instructor. https:// doi.org/10.1094/PHI-I-2003-0917-01

Moens, M. Perry, R.N. and Starr, J.L (2009). Meloidogyne species-A diverse group of novel and important plant parasites. In: Root-knot nematodes. (Perry, R.N. Moens, M. and Starr, J. L. Eds.). CAB International. 1-17. https://doi.org/10.1079/9781845934927.0001

Molinari, S. Fanelli, E. and Leonetti, P (2014). Expression of tomato salicylic acid (SA)-responsive pathogenesis-related genes in Mi-1-mediated and SA-induced resistance to root-knot nematodes. Molecular Plant Pathology. 15(3): 255-264. https://doi.org/10.1111/mpp.12085.

Moslemi, F. Fatemy, S. and Bernard, F (2016). Inhibitory effects of salicylic acid on Meloidogyne javanica reproduction in tomato plants. Spanish Journal of Agricultural research. 14(1): 1-7. http://dx.doi.org/10.5424/sjar/2016141-8706 
Naz, I. Juan, E.P. Vivian, B. Saifullah., Sardar, A. and Musharraf, A (2012). Prevalence, incidence and molecular identification of root-knot nematodes of tomato in Pakistan. African Journal of Biotechnology. 11(100): 16546-16556.https://doi.org/10.5897/AJB12.2502

Naz, I. Asad, A.K.R. Masood, T. Baig, A. Siddique, I. and Shamsulhaq. (2020). Biological control of Root Knot nematode, Meloidogyne incognita, in vitro, greenhouse and field in cucumber. Biological Control. https://doi.org/10.1016/j.biocontrol.2020.104429.

Nicholas, S. and Dominique, A. (2019). Hydrogen peroxide metabolism and functions in plants. New Phytologist. 221: 1197-1214. https://doi.org/10.1111/nph.15488.

Pasternak, T. Groot, E.P. Kazantsev, F. Teale, W. Omelyanchuk, N. Kovrizhnykh, V. and Mironova, V.V (2019). Salicylic acid affects root meristem patterning via auxin distribution in a concentrationdependent manner. Plant Physiology. https://doi.org/10.1104/pp.19.00130

Phong, V.N. Phong, T. Oanh, T.T.V. and Đôn, Đ.L (2020). A report of Meloidogyne javanica on black pepper (Piper nigrum) in Binh Phuoc Province, Vietnam. Australasian Plant Dis. Notes. 15(18). https://doi.org/10.1007/s13314-020-00387-8

Pietrowska, E. Różalska, S. Kaźmierczak, A. Nawrocka, J. and Małolepsza, U (2014). Reactive oxygen and nitrogen (ROS and RNS) species generation and cell death in tomato suspension cultures-Botrytis cinerea interaction. Protoplasma. https://doi.org/10.1007/s00709-014-0680-6

Ravindra, H. Manu, G.T. Latha, M. Mukesh, S. Murali, R. and Narasimhamurthy, H.B (2014). Incidence of root-knot nematode (Meloidogyne incognita) in black pepper in Karnataka. Journal of Entomology and Nematology. 6(4): 51-55. https://doi.org/10.5897/JEN2013.0089. Retrieved from https://www.researchgate.net/publication/284357394_Incidence_of_root-knot_ nematode_Meloidogyne_incognita_in_black_pepper_in_Karnataka. Accessed date: April 06, 2020

Santamaria, M. Arnaiz, A. Gonzalez-Melendi, P. Martinez, M. and Diaz, I (2018). Plant Perception and Short-Term Responses to Phytophagous Insects and Mites. International Journal of Molecular Sciences. 19(5). https://doi.org/10.3390/ijms19051356

Santos, J.M. Ferraz, S. and Oliveira, L.M (1981). Efeito de cloreto de potássio sobre a formação de galhas e a reprodução de Meloidogyne exigua em mudas de cafeeiro. Turrialba. 28: 580-587.

Sharma, P. Jha, A.B. Dubey, R.S. and Pessarakli, M (2012). Reactive Oxygen Species, Oxidative Damage, and Antioxidative Defense Mechanism in Plants under Stressful Conditions. Journal of Botany. https://doi.org/10.1155/2012/217037

Sim, S.L. and Rosmah, J (2011). Botany and varietal improvement. In: Pepper Production Technology in Malaysia. (Sim, S.L. and Lai, K.F. Eds.). Malaysian Pepper Board, Sarawak, Malaysia. 7-55.

Trinh, T.T.T. (2010). Incidence and effect of Meloidogyne incognita (Nematoda: meloidogyninae) on black pepper plants in Vietnam. .... Retrieved from https://www.biw.kuleuven.be/dtp/tro/PhDTRPL-pdf/PhD-Thuy.pdf. Accessed date: April 01, 2020

Vicente, M.R.S. and Plasencia, J. (2011). Salicylic acid beyond defence: its role in plant growth and development. Journal of Experimental Botany. 62(10): 3321-3338. https://doi.org/10.1093/ jxb/err031 
Wang, C. Zhang, S. Wang, P. Hou, J. Qian, J. Ao, Y. and Li, L (2011). Salicylic acid involved in the regulation of nutrient elements uptake and oxidative stress in Vallisneria natans (Lour.) Hara under Pb stress. Chemosphere. 84(1): 136-142. https://doi.org/10.1016/j.chemosphere.2011.02.026

Whitehead, A.G. and Hemming, J.R. (1965). A comparison of some quantitative methods of extracting small vermiform nematodes from soil. Annals of Applied Biology. 55(1): 25-38. https://doi. org/10.1111/j.1744-7348. 1965.tb07864.x

Zhan, L. De-Liang, P. Xu-Li, W. Ling-An, K. Huan, P. Shi-Ming, L. Ying, L. and Wen-Kun, H (2018). Priming effect of root-applied silicon on the enhancement of induced resistance to the root-knot nematode Meloidogyne graminicola in rice.... Retrieved from https://bmcplantbiol. biomedcentral.com/articles/10.1186/s12870-018-1266-9. Accessed date: April 01, 2020 